\title{
Impact of multidisciplinary collaborative pharmaceutical care on knowledge, adherence, and efficacy of hormone therapy in climacteric women
}

This article was published in the following Dove Press journal:

Patient Preference and Adherence

Min Lu'

Ying Zhou'

Baojing Wang ${ }^{2}$

ZheWen $\mathrm{Hu}^{3}$

Ying $\mathrm{Du}^{2}$

ShiFang Liu ${ }^{2}$

XiuFeng Lin $^{2}$

YiMin Cui'

HongYan Jin ${ }^{2}$

'Department of Pharmacy, Peking University First Hospital, Beijing, People's Republic of China;

${ }^{2}$ Department of Obstetrics and Gynecology, Peking University First Hospital, Beijing, People's Republic of China; ${ }^{3}$ Department of Nutrition, Peking University First Hospital,

Beijing, People's Republic of China

Correspondence: HongYan Jin Department of Obstetrics and Gynecology, Peking University First Hospital, I Xi Anmen Street, West District, Beijing 100034, People's

Republic of China

Tel +86 I0 83573859

Email maggijhy@163.com

YiMin Cui

Department of Pharmacy, Peking University First Hospital, 6 Da Hong Luo Chang Street, West District, Beijing 100034, People's Republic of China

Tel +861066155258

Fax +86 I0 66I5 5258

Email cuiymzy@।26.com
Background: The objective of this study was to evaluate the impact of pharmaceutical care on the knowledge, adherence, and efficacy of hormone therapy in climacteric women participated in multidisciplinary collaborative clinic, launched by Peking University First Hospital (Beijing, People's Republic of China) in 2012.

Methods: A total of 296 patients were recruited (intervention group $n=150$, control group $\mathrm{n}=146$ ). The patients in the intervention group visited the multidisciplinary collaborative clinic for their initial hormone therapy, receiving individualized pharmaceutical care (PC), whereas the control group visited only the general clinic without PC. The pill count method, knowledge assessment questionnaire (Cronbach's $\alpha=0.80$ ), and the modified Kupperman Index were used to assess the knowledge, adherence, and efficacy at months 3, 6, and 12.

Results: The intervention group, which received PC, showed significantly higher and better knowledge, adherence, and efficacy than the control group, demonstrating the effectiveness of the PC provided. The knowledge scores of the intervention and control groups at months 3, 6 , and 12 were (73.12 vs 59.28), (77.63 vs 66.19$)$, and ( 80.81 vs 66.64$)$; the data for adherence were $(90.97 \%$ vs $82.17 \%)$, (93.21\% vs $87.79 \%)$, and (95.81\% vs $93.38 \%$ ); and the values of the modified Kupperman Index were (17.15 vs 24.05), (13.22 vs 22.01), and (12.21 vs 23.15), respectively.

Conclusion: PC improved the knowledge, adherence, and efficacy of hormone therapy in climacteric women. Therefore, the multidisciplinary collaborative model investigated in our study should be advocated in other health care institutions for the benefit of more patients. Further large-sample and long-term studies should be conducted to evaluate the effects of PC on patient clinical outcomes, including its impact on the safety and efficacy of long-term use of hormone therapy, as well as the economic benefits.

Keywords: pharmaceutical care, multidisciplinary collaborative care, menopausal women, hormone therapy

\section{Introduction}

The climacteric period is a physiological stage that women go through in the transition from adulthood to old age. During the process of ovarian aging, menopausal women may experience menstrual disorders, vasomotor dysfunction (eg, hot flashes, night sweats), genitourinary symptoms (eg, vaginal irritation and itching, and incontinence), and neuropsychiatric symptoms (eg, memory loss, depression) caused by sex hormonal changes. Menopause is also considered to be the initial stage of chronic diseases, such 
as osteoporosis, cardiovascular disease, and Alzheimer's disease, although no clear evidence exists. Thus, climacteric women should undergo regular, effective disease screening and health education activities based on a multidisciplinary medical care approach. ${ }^{1,2}$

With the extension of human life expectancy, middleand older-aged women have formed a huge population. Currently, the women aged 40-60 years account for $11.28 \%$ of our population, and the number of women over 50 years in the People's Republic of China is estimated to increase to more than 280 million by 2030 . Improving the quality of life in old age has been listed as one of the 3 major themes of health promotion in the 21 st century by the World Health Organization (WHO). Menopause health care aims at health promotion in climacteric women, delaying the occurrence of diseases and laying the foundation for health in old age. ${ }^{3}$

Hormone therapy (HT) is the most effective treatment for climacteric-related syndrome. The benefits and risks of HT for women have remained controversial for decades. The latest findings of Women's Health Initiative trials showed that there was no long-term increase in either all-cause or cause-specific mortality among menopausal women during the cumulative 18-year follow-up. These women received HT for up to 5.6 years (combination of estrogen plus progestin HT group) and another received it for up to 7.2 years (estrogen-alone group). ${ }^{4}$ Rational use of HT is a prerequisite for maximizing the benefits of patient. Pharmacists now have the opportunity to assist patients to use HT correctly by providing individualized pharmaceutical care (PC). The first clinic for climacteric women in the People's Republic of China was launched at Peking University First Hospital. In that clinic, using a multidisciplinary collaborative model, a physician, pharmacist, dietitian, and nurse can work together to optimize the clinical outcomes of climacteric women. Therefore, the primary objective of this study was to evaluate the impact of PC on the medication adherence, knowledge, and efficacy of HT in climacteric women.

\section{Methods}

\section{Setting}

This study was conducted from May 2015 to May 2017 at Peking University First Hospital. Patients enrolled during the period from May 2015 to May 2016 were followed up for 1 year, until May 2017. Pharmacists provided individualized medication guidance and counseling, and conducted group sessions in the form of lectures, during which pharmacists introduced the basics and specifics of the rational use of HT. The aim of this study was to assess the impact of PC provided by pharmacist on the knowledge, adherence, and efficacy of HT in climacteric women. The study was approved by the Ethics Committee of Peking University, and all patients signed informed consent forms.

\section{Patients}

Inclusion criteria were as follows: aged 40 years or older, diagnosed with climacteric-related syndrome, and recommendation to use HT.

Exclusion criteria were as follows: patients treated with progestin alone, presence of communication and language barriers, and unwillingness to participate in the follow-up.

\section{Procedure}

Patients who met the inclusion criteria were enrolled in the intervention group based on their willingness to attend the multidisciplinary collaborative menopause clinic. The patients in the intervention group received standard PC by a trained pharmacist, which included face-to-face counseling, guidance on goals, medication usage, side effects, and precautions. Emphasis was also made on the importance of adherence to HT and other combined medication. The materials used included a booklet about HT, a personalized medication regimen, and a follow-up schedule. The pharmacist spent approximately 25 minutes per intervention patient.

Similarly, according to the patients' willingness, those who met the criteria for inclusion but attended only the general clinic, without provision of standardized PC, were enrolled in the control group.

The length of the follow-up period in this study was 12 months. All patients were asked questions by phone by the pharmacist at months 3,6, and 12 . The knowledge, adherence, and efficacy of HT were assessed based on validated scales. The patients in the intervention group also received referral reminders and necessary counseling during the follow-up period (Figure 1).

\section{Outcomes}

The primary outcomes measured were medication adherence, patient's knowledge about the treatment, and its efficacy.

A knowledge questionnaire (Cronbach's $\alpha=0.80$ ) was used to measure the patient's adherence and knowledge. The questionnaire involved 37 questions on four aspects, including general information on drugs, adverse drug reactions (ADRs) and precautions, treatment options, and follow-up procedures. The score of the questionnaire was finally converted into percentile.

The pill count method was applied to assess adherence, expressed as the doses actually taken relative to the doses prescribed in the current cycle. ${ }^{5}$ The patients of the 2 groups returned to the clinic monthly to refill or adjust 


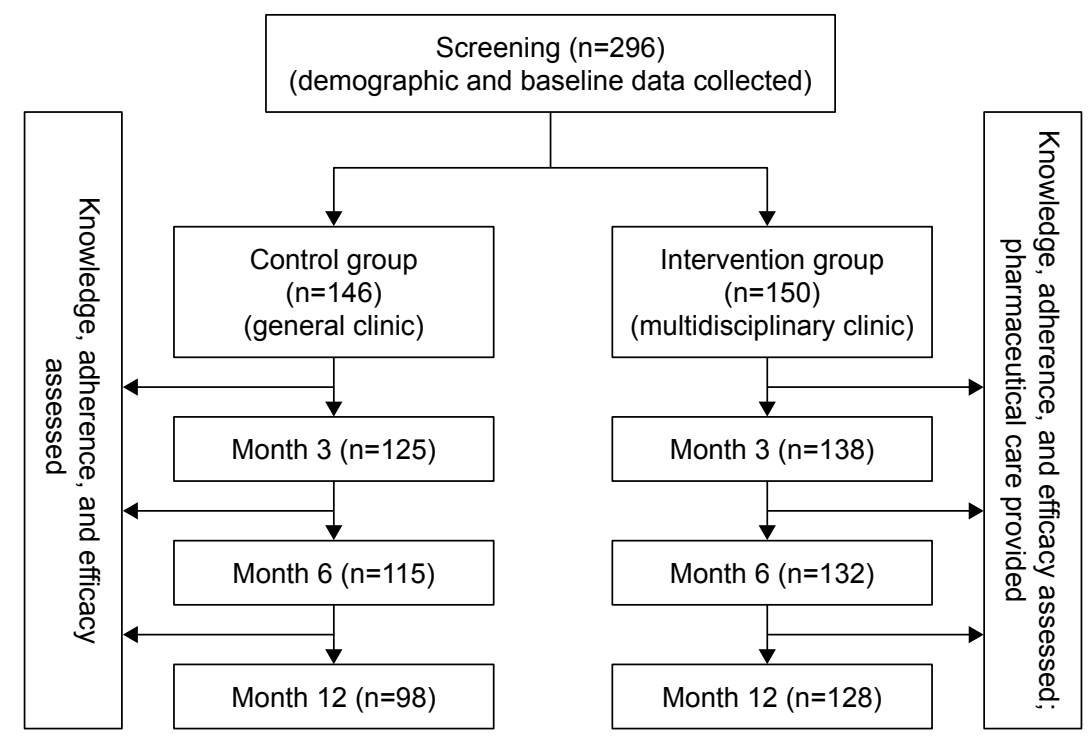

Figure I Research flowchart of the study.

their prescriptions, and we counted the number of tablets left at each visit. The quality of all dispensed hormonal medications as well as the time and date of the prescription issuance were recorded in the hospital information system (HIS). Then, we used the data retrieved from HIS to calculate patient adherence. The modified Kupperman Index $(\mathrm{KI})^{6}$ is widely used internationally to evaluate the severity of climacteric-related symptoms. However, taking into account the impact of the various physical, social, regional, and cultural factors, a modified $\mathrm{KI}^{7}$ has been validated and is currently used in the People's Republic of China,${ }^{8}$ and thus in our study also. The modified KI consists of 13 items. Adjusted by the weighting factor of each question, the score reaches a total of up to 63 points. The severity of climacteric-related symptoms is represented by the score ranges of $0-6,7-15,16-30$, and $>30$ as none, mild, moderate, and severe, respectively.

\section{Statistical analysis}

Data were analyzed using SPSS version 22 (IBM Corporation, Armonk, NY, USA). Continuous variables were expressed as mean \pm standard deviation (SD), whereas categorical variables were expressed as an absolute value (number) and frequency (percentage). The continuous variables of the 2 groups in the demographic data were analyzed using independent samples $t$-test and the categorical data by the $\chi^{2}$ test. Comparison of the impact of PC on knowledge, adherence, and efficacy between the two groups was made by the nonparametric Mann-Whitney $U$-test when normality assumptions could not be fulfilled. All $P$-values $<0.05$ were considered statistically significant.

\section{Results}

\section{Patients}

A total of 296 patients were recruited in the 2 groups (intervention $n=150$, control $n=146$ ). There was no difference in the baseline characteristics between the control and intervention groups concerning the age of the patients, the duration and severity of symptoms, body mass index (BMI), level of education, and exercise (Table 1). Finally, 98 patients in the control group completed the entire follow-up, but 48 patients dropped out due to adverse reactions (17 cases), poor adherence (14 cases), or lost to follow-up (17 cases). On the other hand, 128 patients in the intervention group completed the entire follow-up, and only 22 patients dropped out due to adverse reactions (13 cases), poor adherence (6 cases), or lost to follow-up (3 cases).

\section{Knowledge}

Compared with the control group, the intervention group had higher knowledge scores, (73.12 vs 59.28$)$, (77.63 vs 66.19), and (80.81 vs 66.64), at months 3,6 , and 12 with statistically significant differences (Mann-Whitney $U$-test) (Table 2), demonstrating the positive impact of PC. The knowledge scores of both groups continued to improve during the follow-up period.

\section{Adherence}

The adherence levels of the 2 groups were assessed by the pill count method. Our results showed that the intervention group had better adherence ( $90.97 \%$ vs $82.17 \%),(93.21 \%$ vs $87.79 \%$ ), and (95.81\% vs $93.38 \%$ ) than the control group at month 3,6 , and 12 with statistically significant differences 
Table I Baseline characteristics of the control and intervention groups

\begin{tabular}{|c|c|c|c|c|}
\hline Items & Control $(n=146)$ & Intervention $(n=150)$ & t-valuel $\chi^{2}$ & $P$-value \\
\hline Average age & $47.13 \pm 7.55$ & $45.13 \pm 6.98$ & 1.492 & 0.136 \\
\hline Duration of symptoms & $2.50 \pm 0.75$ & $2.28 \pm 0.46$ & 1.645 & 0.102 \\
\hline Modified KI & $33.59 \pm 4.20$ & $34.04 \pm 4.57$ & -0.718 & 0.474 \\
\hline BMI, $n$ & & & $\mathrm{I} .874$ & 0.599 \\
\hline$<18.5$ & 15 & 17 & & \\
\hline $18.5-24.9$ & 45 & 50 & & \\
\hline $25-29.9$ & 58 & 63 & & \\
\hline$\geq 30$ & 28 & 20 & & \\
\hline Education level, $n$ & & & 0.468 & 0.791 \\
\hline Primary education & 15 & 18 & & \\
\hline Secondary education & 93 & 90 & & \\
\hline Undergraduate/postgraduate & 38 & 42 & & \\
\hline Exercise frequency (times/wk), $n$ & & & 0.293 & 0.588 \\
\hline$<3$ & 88 & 95 & & \\
\hline$\geq 3$ & 58 & 55 & & \\
\hline
\end{tabular}

Note: Data shown as mean \pm standard deviation unless indicated otherwise.

Abbreviations: BMI, body mass index; KI, Kupperman Index.

(Table 3). It is noteworthy that the patients that received PC had better adherence.

\section{Efficacy}

The symptoms of both groups improved after receiving HT. The patients in the intervention group had better modified

Table 2 Knowledge score of the control and intervention groups during the follow-up period

\begin{tabular}{|c|c|c|c|c|c|c|}
\hline \multirow[t]{2}{*}{ Month 3} & \multicolumn{2}{|c|}{$\begin{array}{l}\text { Control } \\
(n=125)\end{array}$} & \multicolumn{2}{|c|}{$\begin{array}{l}\text { Intervention } \\
(\mathrm{n}=138) \\
\end{array}$} & \multirow[t]{2}{*}{$\mathbf{z}$} & \multirow[t]{2}{*}{$\overline{P \text {-value }}$} \\
\hline & Mean & SD & Mean & SD & & \\
\hline form & 59.66 & 31.59 & 77.52 & 23.89 & -3.25 & $0.001 *$ \\
\hline ADR and precautions & 54.05 & 21.52 & 66.33 & 13.15 & -3.34 & $0.001 *$ \\
\hline Treatment options & 43.76 & 23.04 & 58.17 & 17.92 & -3.52 & $<0.00 I^{*}$ \\
\hline Follow-up procedures & 79.66 & 18.39 & 90.46 & 12.42 & -3.87 & $<0.00 I^{*}$ \\
\hline Total scores & 59.28 & 21.11 & 73.12 & 15.17 & -4.12 & $<0.00 I^{*}$ \\
\hline \multirow[t]{2}{*}{ Month 6} & \multicolumn{2}{|c|}{$\begin{array}{l}\text { Control } \\
(n=\mid 15)\end{array}$} & \multicolumn{2}{|c|}{$\begin{array}{l}\text { Intervention } \\
(n=132)\end{array}$} & $\mathbf{z}$ & \\
\hline & Mean & SD & Mean & SD & & \\
\hline General information & 67.89 & 25.83 & 83.21 & 20.32 & -3.49 & $<0.00 I^{*}$ \\
\hline ADR and precautions & 63.1 & $|5.6|$ & 70.11 & 14.36 & -1.93 & 0.054 \\
\hline Treatment options & 51.44 & 20.32 & 65.07 & 17.32 & -3.76 & $<0.00 I^{*}$ \\
\hline Follow-up pro & 82.33 & 16.36 & 92.11 & 11.12 & -3.62 & $<0.00 I^{*}$ \\
\hline Total scores & 66.19 & 19.01 & 77.63 & 14.13 & -4.57 & $<0.00 I^{*}$ \\
\hline \multirow[t]{2}{*}{ Month 12} & \multicolumn{2}{|c|}{$\begin{array}{l}\text { Control } \\
(n=98)\end{array}$} & \multicolumn{2}{|c|}{$\begin{array}{l}\text { Intervention } \\
(n=\mid 28)\end{array}$} & \multirow[t]{2}{*}{$z$} & \multirow[t]{2}{*}{$P$-value } \\
\hline & Mean & SD & Mean & SD & & \\
\hline General information & 70.59 & 25.04 & 85.77 & 21.25 & -3.85 & $<0.00$ I $^{*}$ \\
\hline ADR and precautions & 61.16 & 17.78 & 74.18 & 12.18 & -3.60 & $<0.00 I^{*}$ \\
\hline Treatment options & 51.05 & 22.14 & 68.42 & 18.19 & -4.58 & $<0.00 I^{*}$ \\
\hline Follow-up procedures & 83.77 & 17.94 & 94.86 & 8.65 & -3.75 & $<0.00 I^{*}$ \\
\hline Total scores & 66.64 & 17.24 & 80.81 & 13.70 & -5.34 & $<0.00 I^{*}$ \\
\hline
\end{tabular}

Note: *Statistically significant $(P<0.05)$.

Abbreviations: ADR, adverse drug reaction; SD, standard deviation.
KI scores than those in the control group (a lower score means better efficacy) (17.15 vs 24.05), (13.22 vs 22.01), and (12.21 vs 23.15) at months 3, 6, and 12 (Table 4). These results obtained further confirmed that PC can optimize patient outcomes.

\section{Discussion}

As is known, adherence of HT is suboptimal..$^{9-12}$ The 2 most common reasons are patient's concerns about cancer and vaginal bleeding. ${ }^{13-16}$ In our study, the knowledge, adherence, and efficacy of HT in both groups continued to improve over time. However, the patients of the intervention group, who received $\mathrm{PC}$, had better and higher scores with statistically significant differences. Moreover, the dropout rate in the intervention group (22/150) was lower than that in the control group (48/146). Our results confirmed the positive impact of PC on the clinical outcomes of HT in climacteric women. The involvement of the pharmacist helped patients obtain a better understanding and confidence in the initial stage of HT. Additionally, the consultation provided by the pharmacist during the follow-up period further improved adherence, eventually resulting in achieving the desired efficacy.

Table 3 Adherence of the 2 groups, assessed by the pill count method

\begin{tabular}{|c|c|c|c|c|c|c|}
\hline & \multicolumn{2}{|c|}{ Control } & \multicolumn{2}{|c|}{ Intervention } & \multicolumn{2}{|c|}{$\begin{array}{l}\text { Mann-Whitney } \\
\text { U-test }\end{array}$} \\
\hline & Mean & SD & Mean & SD & $\mathbf{z}$ & $P$-value \\
\hline Month 3 & 82.17 & 10.95 & 90.97 & 5.25 & -1.99 & $0.046 *$ \\
\hline Month 6 & 87.79 & 7.37 & 93.21 & 3.43 & -2.43 & $0.014 *$ \\
\hline Month 12 & 93.38 & 5.13 & 95.81 & 6.42 & -2.19 & $0.027^{*}$ \\
\hline
\end{tabular}

Note: *Statistically significant $(P<0.05)$.

Abbreviation: SD, standard deviation. 
Table 4 Modified $\mathrm{KI}$ scores in the control and intervention groups

\begin{tabular}{|c|c|c|c|c|c|c|}
\hline & \multicolumn{2}{|c|}{ Control } & \multicolumn{2}{|c|}{ Intervention } & \multicolumn{2}{|c|}{$\begin{array}{l}\text { Mann-Whitney } \\
\text { U-test }\end{array}$} \\
\hline & Mean & SD & Mean & SD & $z$ & $P$-value \\
\hline Month 3 & 24.05 & 9.76 & 17.15 & 7.64 & -3.627 & $<0.00 I^{*}$ \\
\hline Month 6 & 22.01 & 10.40 & 13.22 & 6.98 & -3.666 & $<0.00 I^{*}$ \\
\hline Month 12 & 23.15 & 9.3 & 12.21 & 7.64 & -4.108 & $<0.00 I^{*}$ \\
\hline
\end{tabular}

Note: *Statistically significant $(P<0.05)$.

Abbreviations: KI, Kupperman Index; SD, standard deviation.

The results of the present investigation are similar to those of other studies on the impact of PC on the improvement of patient's knowledge, adherence, and efficacy. ${ }^{17-19}$ Nevertheless, to the best of our knowledge, our research is the first to explore the impact of PC on hormonal treatment in climacteric women. One publication reported that climacteric women need more access to information on HT as their physicians cannot provide extensive information and education. ${ }^{20}$ In the current medical environment, physicians are too overloaded to provide comprehensive guidance to patients, especially in the People's Republic of China. Thus, there are opportunities for pharmacists to collaborate with physicians and other staff to provide multidisciplinary care to climacteric women. Such a favorable interaction will improve their knowledge, adherence, and efficacy of HT, which will increase the benefits to the patients. This model was also acknowledged to save medical human resources and reduce the medical costs. ${ }^{21}$

This study was not randomized. Because the patients had to pay an additional consultation fee for therapy in a multidisciplinary care clinic, the grouping of the study was based on the patient's willingness. The baseline characteristics of the 2 groups were comparable without statistically significant differences. Nonetheless, the dropout rate in the control group was higher than that in the intervention group $(32.9 \%$ vs $14.7 \%$ ). Poor adherence and lost to follow-up were the main reasons for dropout in the control group. Therefore, the actual situation of knowledge, adherence, and efficacy in the control group might have been even worse than that found in the results of this study.

\section{Limitations}

There are some limitations in our study. First, it was carried out only at one single center, and the sample size was small. Thus, the results cannot be extrapolated to all climacteric women in the People's Republic of China. Second, the duration of the follow-up was not sufficiently long to observe serious ADR (eg, cancer, thrombosis); hence, we will continue to follow-up to obtain more information. Third, the results cannot rule out the influence of other members of the team. Meanwhile, the regular follow-up of the pharmacist might inevitably have exerted certain positive effects in the control group.

\section{Conclusion}

In our study, PC had positive effects on the knowledge, adherence, and efficacy of HT in climacteric women in the People's Republic of China. This is a preliminary study that provides evidence which can serve as the foundation for more rigorous and comprehensive randomized controlled trials. Further controlled studies with larger samples and longer follow-up periods should be conducted to verify the influence of PC on the safety, efficacy, and cost-effectiveness of HT in climacteric women. A multidisciplinary care model should be advocated in more medical institutions to benefit more patients, especially those with chronic diseases who need long-term management.

\section{Disclosure}

The authors report no conflicts of interest in this work.

\section{References}

1. Shepherd JE. Effects of estrogen on cognition mood, and degenerative brain diseases. J Am Pharm Assoc. 2001;41(2):221-228.

2. Rebar R, Nachtigall L, Avis N, et al. Clinical challenges of perimenopause: consensus opinion of The North American Menopause Society. Menopause. 2000;7(1):5-13.

3. Chinese Preventive Medicine Women's Health Branch, Menopause Health Care Group. Guideline on Menopause Women's Health (2015). J Pract Gynecol Endocrinol. 2016;3(2):21-33.

4. Manson JE, Aragaki AK, Rossouw JE, et al. Menopausal hormone therapy and long-term all-cause and cause-specific mortality: the women's health initiative randomized trials. JAMA. 2017;318(10): 927-938.

5. Steiner JF, Prochazka AV. The assessment of refill compliance using pharmacy records: methods, validity, and applications. J Clin Epidemiol. 1997;50(50):105-116.

6. Kupperman HS, Blatt MH, Wiesbader H, Filler W. Comparative clinical evaluation of estrogenic preparations by the menopausal and amenorrheal indices. J Clin Endocrinol Metab. 1953;13(6):688-703.

7. Cao ZY. Chinese Obstetrics and Gynecology. Beijing, People's Republic of China: People's Medical Publishing House; 2005.

8. Minfang T, Hongfang S, Changbing L, et al. Correlation between the modified Kupperman index and the Menopause Rating Scale in Chinese women. Patient Prefer Adherence. 2013;7:223-229.

9. Stumpf PG, Trolice MP. Compliance problems with hormone replacement therapy. Obstet Gynecol Clin North Am. 1994;21(2):219-226.

10. Ryan PJ, Harrison R, Blake GM, Fogelman I. Compliance with hormone replacement therapy (HRT) after screening for postmenopausal osteoporosis. Br J Obstet Gynaecol. 1993;100(4):399-400.

11. Torgerson DJ, Donaldson C, Russell IT, Reid DM. Hormone replacement therapy: compliance and cost after screening for osteoporosis. Eur J Obstet Gynecol Reprod Biol. 1995;59(1):57-60.

12. Cano A. Compliance to hormone replacement therapy in menopausal women controlled in a third level academic center. Maturitas. 1994;20(2-3):91-99. 
13. Schiff I, Rebar RW, Cramer JA, et al. Achieving long-term continuance of menopausal ERT/HRT: consensus opinion of the North American Menopause Society. Menopause. 1998;5(2):69-76.

14. Ravnikar VA. Compliance with hormone therapy. Am J Obstet Gynecol. 1987;156(5):1332-1334.

15. Ferguson KJ, Hoegh C, Johnson S. Estrogen replacement therapy: a survey of women's knowledge and attitudes. Arch Intern Med. 1989;149(1):133-136.

16. Nachtigall LE. Enhancing patient compliance with hormonal replacement therapy at menopause. Obstet Gynecol. 1990;75(4):380.

17. Bluml BM, McKenney JM, Cziraky MJ. Pharmaceutical care services and results in project ImPACT: hyperlipidemia. J Am Pharm Assoc. 2000;40(2):157-165.
18. Kripalani S, Yao X, Haynes RB. Interventions to enhance medication adherence in chronic medical conditions: a systematic review. Arch Intern Med. 2007;167(6):540-550.

19. Taitel M, Jiang J, Rudkin K, Ewing S, Duncan I. The impact of pharmacist face-to-face counseling to improve medication adherence among patients initiating statin therapy. Patient Prefer Adherence. 2012;6: 323-329.

20. Connelly MT, Ferrari N, Hagen N, Inui TS. Patient-identified needs for hormone replacement therapy counseling: a qualitative study. Ann Intern Med. 1999;131(4):265-268.

21. Batalden PB, Davidoff F. What is "quality improvement" and how can it transform healthcare? Qual Saf Health Care. 2007;16(1):2-3.

\section{Publish your work in this journal}

Patient Preference and Adherence is an international, peer-reviewed, open access journal that focuses on the growing importance of patient preference and adherence throughout the therapeutic continuum. Patient satisfaction, acceptability, quality of life, compliance, persistence and their role in developing new therapeutic modalities and compounds to optimize clinical outcomes for existing disease states are major areas of interest for the journal. This journal has been accepted for indexing on PubMed Central. The manuscript management system is completely online and includes a very quick and fair peer-review system, which is all easy to use. Visit http://www dovepress.com/testimonials.php to read real quotes from published authors. 